\title{
Reserch автісі: Credibility of different sources and channels of agriculture information as perceived by the ber growers
}

\author{
B.L. DHAYAL* AND B.C. BOCHALYA
}

Article Chronicle: Received : 01.12.2014;

Revised : 22.12.2014; Accepted : 08.01.2015

KeY Words : Credibility, Communication, Sources, Channels, Ber, Peripheral, Distant, Growers

Author for correspondence :

\section{B.L. DHAYAL}

Krishi Vigyan Kendra, Vadodara,(GUJARAT) INDIA

Email: dhayalextn@

yahoo.co.in

See end of the article for authors' affiliations
SUMMARY : Credibility of information sources and channels affect the adoption of improved agricultural practices by farmers. Credibility refers to perceived trustworthiness and expertise accorded to a source or channel by its audience at any given time. Therefore, sources and channels of agriculture information play major role in diffusion of agriculture innovations. This study was conducted in Chomu tehsil of Jaipur district of Rajasthan, from Chomu tehsil ten villages were selected on the basis of highest area and production of ber. A sample of 100 ber growers was selected by simple random sampling technique for the study purpose in such a manner that the number of ber growers selected was proportional to the size of the selected village. It was found that majority of the ber growers $(76.00 \%)$ belonged to medium credibility level followed by 13.00 per cent having low credibility and only 11.00 per cent were having high credibility to different sources and channels of agriculture information. About 85.11 per cent peripheral ber growers had high credibility to different sources and channels, whereas 67.93 per cent distant ber growers had high credibility to different sources and channels of information. It was further found that the 'progressive farmers' (MPS 79.33) was identified as the most credible personal localite source by the ber growers. The peripheral ber growers accorded their highest credibility to 'friends' (MPS 77.30), whereas 'progressive farmers' (MPS 84.90) was perceived as the most credible personal localite source of agriculture information by the distant ber growers. The 'agriculture supervisor' (MPS 84.33) was the most credible personal cosmopolite sources by the ber growers. The peripheral ber growers also accorded their highest credibility to 'agriculture supervisor' (MPS 95.03), whereas the 'KVK officials' (MPS 76.73) were perceived as the most credible personal cosmopolite source of agriculture information by the distant ber growers. The 'group meeting' was the most credible personal cosmopolite channel among the peripheral ber growers (MPS 81.56) and distant ber growers (MPS 86.79) in the study area. The 'radio' (MPS 85.33) was perceived as the most credible impersonal cosmopolite channels by the ber growers. The peripheral ber growers accorded their highest credibility to 'newspaper' (MPS 85.11), whereas 'radio' (MPS 87.42) was perceived as the most credible impersonal cosmopolite channel of agriculture information by the distant ber growers. The 'impersonal cosmopolite channels' (MPS 71.70) and 'personal localite sources' (MPS 67.72) were the most credible sources and channels. The 'impersonal cosmopolite channels' were the most credible channels-9 among the peripheral ber growers (MPS 71.13) and distant ber growers (MPS 72.20) in the study area.

How to cite this article : Dhayal, B.L. and Bochalya, B.C. (2015). Credibility of different sources and channels of agriculture information as perceived by the ber growers. Agric. Update, 10(1): 17-22. 